\title{
Basics of mechanical ventilation for non-aneasthetists. Part 2: Clinical aspects
}

\begin{abstract}
Invasive and non-invasive mechanical ventilation (MV) continues to be the most significant life support method. It is, however, coupled with many risks. Historically, concepts of MV did focus on improving the arterial blood gas results rather than preventing harmful side-effects of positive pressure ventilation. Since then, multiple studies exploring this matter emerged and led to the protective MV concept. The golden mean between assuring the best oxygenation and limiting the ventilator-induced lung injury (VILI) is still a matter of debate. These considerations are especially impactful while treating patients with adult respiratory distress syndrome (ARDS), where the limitation of MV's negative effect is specifically important. This paper explores the protective ventilation concept and clinical implications of the latter.
\end{abstract}

Key words: mechanical ventilation, acute respiratory distress syndrome, non-invasive ventilation, protective ventilation, ventilator-induced lung injury

Adv Respir Med. 2020; 88: 580-589

\section{Introduction}

Mechanical ventilation must be carried out exceptionally cautiously and take into account: indications and contraindications for its implementation, the clinical condition of the patient, the technical capabilities of the ward, and the skills of the staff. It is important to adjust therapy to the patient, not vice versa - the way of ventilation changes over time, taking into account, in particular, the current results of arterial blood tests which reflect the progression or regression of the disease. It is advisable to perform imaging and diagnostic-therapeutic bronchofibersocopy tests, especially in patients with known atelectasis. Even the safest mechanical ventilation poses a risk, the consequences of which affect the patient. Lung damage is an almost inevitable complication of respiratotherapy.

\section{Ventilator-induced lung injury}

Ventilator-induced lung injury (VILI) is a form of ventilator-associated lung injury (VALI), which is a broader concept and refers to all forms of lung damage in ventilated patients. Ventilator-induced lung injury means that the connection between ventilation and damage has been proven. The use of too high pressures in the respiratory tract leads to damage in the lung tissue, so-called barotrauma, which from today's perspective, may seem like a historical issue. In the past, when the concept of safe ventilation was not present, the formation of subcutaneous emphysema, pneumothorax, pneumomediastinum, or air embolism was not uncommon [1]. The presence of such complications indicates the macroscopic disintegration of the lungs. It must be noted, however, that the direct cause of such damage is not the pressure in the respiratory tract, but the pressure applied to the lungs themselves, where the most important role is played by the so-called transpulmonary pressure (the difference between the pressure in the alveoli and the pressure in the pleural cavity). Dreyfuss et al. in the 1980s conducted an experiment in which rats were ventilated with high pressure, with one group of animals wearing stripes to prevent lung and

Address for correspondence: Łukasz J Krzych, Chair and Department of Anaesthesiology and Intensive Care, Medical University of Silesia in Katowice, Poland; e-mail: I.krzych@wp.pl DOI: 10.5603/ARM.a2020.0159

Received: 27.04.2020

Copyright (C) 2020 PTChP

ISSN 2451-4934 
thoracic expansion during ventilation - the other did not. In both groups, very high pressures were achieved in the respiratory tract, but there was no lung damage in the group of rats with clenched belts, while individuals without belts experienced damage [2]. This experiment, thanks to the artificial reduction in the compliance of the chest, achieved low values of transpulmonary pressure (due to increased pressure in the pleural cavity), which prevented barotrauma (and VILI). The reason why rats without a stiffened chest showed more considerable lung damage was therefore caused not by the pressure itself, but the higher respiratory volume obtained - hence the new term emerged - volutrauma. Considerations on VILI can be further extended with an analysis of the formula for transpulmonary pressure:

$$
\mathrm{P}_{\mathrm{L}}\left[\mathrm{cmH}_{2} \mathrm{O}\right]=\mathrm{K} \times \mathrm{V}_{\mathrm{T}} / \text { FRC. }
$$

Where " $\mathrm{P}_{\mathrm{L}}$ " means transpulmonary pressure, "K" - specific pulmonary elastance, " $\mathrm{V}_{\mathrm{T}}$ " - respiratory volume, and "FRC" is the functional residual capacity of the lungs. The equation above directly combines the respiratory volume with transpulmonary pressure, meaning that the concept of pressure and volume damage is closely related. An equally important component of the design is also FRC which is reduced, e.g., acute respiratory distress syndrome [3], increasing $\mathrm{P}_{\mathrm{L}}$. The use of low respiratory volumes reduces transpulmonary pressure, and therefore the risk of VILI [4]. Pumping the air into the lungs by producing positive pressure also carries the risk of cyclic opening and closing of the alveoli. Slutsky et al. in 1997 discovered that such repeated recruitment and derecruitment of the alveoli also harm the tissue by promoting inflammation - this experiment created the concept of atelectrauma [5]. Taking Mead's physical considerations into account and the fact that in partially collapsed lungs (e.g. ARDS), the applied pressure can induce extremely different transpulmonary pressure values - in one place the pressure $\mathrm{P}_{\mathrm{L}}$ may be $30 \mathrm{cmH}_{2} \mathrm{O}$ and in another even $140 \mathrm{cmH}_{2} \mathrm{O}$ (!), which becomes a pressure critically damaging to the lung tissue [6]. As mentioned above, lung damage can be done not only mechanically, but also by induction and promotion of inflammation in the biochemical sense - biotrauma [7]. Mechanical ventilation forces deforming the alveoli also affect immune cells. There is increased secretion of pro-inflammatory cytokines, fibrosis processes and radical stress. It has been documented that after two-hour ventilation with high volumes of rat lungs, TNF- $\alpha$, IL-1- $\beta$, IL-6, IL-10, MIP-2, and IFN- $\gamma$ concentrations increased significantly [8]. Such a cytokine storm can enter the systemic circulation and worsen the course of the underlying lung disease, leading to catastrophic complications [9].

In recent years, attempts have been made to unify the problem of lung damage by creating a formula for the so-called mechanical power (MP), the value of which could reflect the degree of harmfulness of the parameters of the ventilator on the lung tissue. Such formula was proposed by L. Gattinoni et al. [10]:

$$
\begin{gathered}
\mathrm{MP}[\mathrm{J} / \mathrm{min}]=0.0098 \times \mathrm{RR}\left\{\Delta \mathrm{V}^{2}(\mathrm{E}+\mathrm{RR} \times \mathrm{R})\right. \\
+\frac{1}{2} \frac{(1+\mathrm{I}: \mathrm{E})}{60 \times \mathrm{I}: \mathrm{E}} \Delta \mathrm{V} \times \mathrm{PEEP} .
\end{gathered}
$$

Where RR — breaths/min, $\Delta \mathrm{V}$ - respiratory volume, E - respiratory elastance, $\mathrm{R}$ - respiratory resistance, PEEP - positive end-expiratory pressure, I:E - inhalation time-to-exhaust ratio. The clinician should strive to minimise the power of mechanical ventilation even at the expense of lower saturation [permissive hypoxemia $-\mathrm{SaO}_{2}$ between $85-95 \%$ and carbon dioxide retention (permissive hypercapnia $-\mathrm{pCO}_{2} 65-$ $85 \mathrm{mmHg}$ )] [11]. It has been proven that a power greater than $12 \mathrm{~J} / \mathrm{min}$ carries a higher risk of complications [12]. It must be remembered that low MP may not be acceptable in patients with severe ARDS, whose ventilation parameters must be chosen in a way to guarantee the minimum, necessary for survival oxygenation. It is therefore suggested that in mild ARDS, the power should be lower than $17 \mathrm{~J} / \mathrm{min}$, moderate ARDS $<22 \mathrm{~J} / \mathrm{min}$, and in severe $<27 \mathrm{~J} / \mathrm{min}$ [13].

\section{Parameters of safe mechanical ventilation}

The concept of safe mechanical ventilation (LPV) applies to all patient groups, both those with healthy and diseased lungs, that is, both in the operating block and in the ICU. In both groups, complications are observed after the use of such parameters: postoperative respiratory complications in anaesthesiology and a reduction in ventilation time and faster ARDS resolution in intensive care. A protective, cost-effective ventilation strategy in the operating room is not associated with any additional intraoperative risk in the operated persons [15].

Breathing volume $\left(\mathrm{V}_{\mathrm{T}}\right.$, tidal volume) is designed to guarantee an adequate amount of air entering the lungs, and thus delivering oxygen 
and removing carbon dioxide. The higher the respiratory volume, the easier these assumptions are achieved. Unfortunately, excessive respiratory volume leads to lung damage. A number of studies were conducted comparing lower $V_{T}$ values of $6-8 \mathrm{~mL} / \mathrm{kg}$ of ideal body weight (IBW) with higher values of 9-15 mL/kg IBW. In those patients who were treated with small volumes, a decrease in mortality (by 30-40\%), fewer complications and fewer cases of VILI were observed [15]. According to current guidelines, it is therefore recommended to reduce $\mathrm{V}_{\mathrm{T}}$ to $\leq 6-7 \mathrm{~mL} / \mathrm{kg}$ IBW [16], as it leads to relatively small inflation of lung tissue. Breathing volume is the most essential element of the formula for the power of mechanical ventilation. Hence, any efforts to reduce MP should begin with an attempt to optimise this parameter [10].

Plateau pressure is the pressure achieved in the respiratory tract after stopping the inhalation flow and before exhalation - the so-called inhalation pause. It depends on the compliance of the respiratory system and in some way, determines the degree of lung distension. If the patient is ventilated with a safe volume of $6 \mathrm{~mL} / \mathrm{kg}$, the values of this pressure should also be monitored so that they do not exceed $30 \mathrm{cmH}_{2} \mathrm{O}$ [11]. The high value of this parameter is an independent risk factor for death in ventilated patients [17].

Driving pressure (DP) is the difference between plateau pressure and end-expiratory pressure obtained in the airways. It reflects the dynamic changes to which the lung is subjected. Currently, this parameter is considered the most reliable VILI predictor, both in patients with ARDS and in those with healthy lungs undergoing general anaesthesia [18]. It is recommended to reduce the DP to a value below $14 \mathrm{cmH}_{2} \mathrm{O}$ [18]. However, it must be remembered that the driving pressure is not an independent variable. To achieve safe values for this parameter, one needs to modify the plateau pressure (depending on the respiratory volume and pulmonary elastance) and the positive end-expiratory pressure (PEEP) value. However, it must not be the case that, in order to reduce the DP, uncontrolled increases in PEEP values are allowed. It is conceivable that the paradoxically safe value of $\mathrm{DP}=12 \mathrm{cmH}_{2} \mathrm{O}$ can be dangerous if the set PEEP is too high or too low [19].

When a healthy person ends expiration, the respiratory system naturally (thanks to the resistance of the upper respiratory tract) produces some positive pressure so that the alveoli do not collapse [20]. That is why it is so important to produce PEEP during mechanical ventilation. Optimal PEEP can effectively counter lung deprivation, cyclic recruitment and derecruitment of the alveoli (atelectrauma, VILI) and improve gas exchange and the ventilation-perfusion ratio [21]. Insufficient PEEP leads to a deterioration in respiratory work and VILI development. An equally important problem is also the higher value of this parameter: large PEEP, acting on the alveoli, can lead to excessive lung stretching (so-called static strain increase), which elevates inflammation of the tissue and therefore promotes VILI [22]. Excessive PEEP also presses down large pulmonary vessels, impairing venous return, i.e. reducing the cardiac output [23], and also slightly damages the outflow of lymph. It has been documented that $\mathrm{PEEP} \geq 15 \mathrm{cmH}_{2} \mathrm{O}$ is associated with excessive lung stretching and haemodynamic impairment [24]. From the point of view of mechanical power (MP), higher PEEP also means the more required energy needed to be delivered to the patient's lungs, and therefore can contribute to the formation of VILI [10]. The randomised PROVHILO study examined patients undergoing abdominal surgery, ventilated or PEEP $=2 \mathrm{cmH}_{2} \mathrm{O}$ or PEEP $=$ $12 \mathrm{cmH}_{2} \mathrm{O}$. No adverse effects of higher PEEP values were observed, while the lower pressure PEEP group had a detrimental effect of cyclic opening and closing of follicles [25]. Various strategies for ventilation of patients without ARDS ventilated in the intensive care unit were also assessed, where the strategy - low $\mathrm{V}_{\mathrm{T}}\left(<8 \mathrm{~mL} / \mathrm{H}_{2} \mathrm{O}\right)+$ low PEEP $\left(<10 \mathrm{cmH}_{2} \mathrm{O}\right)$ was associated with a shorter stay at the ICU, and the strategy - low $\mathrm{V}_{\mathrm{T}}+$ high PEEP (> $10 \mathrm{cmH}_{2} \mathrm{O}$ ) - was linked with improved

\section{Table 1. The most common causes and classification of acute respiratory distress syndrome (ARDS) [14, self-modification]}

\begin{tabular}{|c|c|c|}
\hline \multicolumn{3}{|c|}{ The most common causes of ARDS } \\
\hline \multicolumn{3}{|l|}{ - Sepsis } \\
\hline \multicolumn{3}{|c|}{ - Severe pneumonia } \\
\hline \multicolumn{3}{|l|}{ - Injuries } \\
\hline \multicolumn{3}{|c|}{ - Aspiration of harmful substances (e.g. stomach content) } \\
\hline \multicolumn{3}{|c|}{ - Other — massive blood transfusions, acute pancreatitis, etc } \\
\hline Mild ARDS & Moderate ARDS & Severe ARDS \\
\hline \multicolumn{3}{|c|}{ Horowitz index $\left(\mathrm{PaO}_{2} / \mathrm{FiO}_{2}\right)$, at PEEP $\geq 5 \mathrm{cmH}_{2} \mathrm{O}$} \\
\hline $300-201$ & $101-200$ & $<100$ \\
\hline
\end{tabular}

$\mathrm{FiO}_{2}$ - oxygen concentration in the respiratory mixture (in decimal numbers): $\mathrm{pO}_{2}$ - partial pressure of oxygen in the arterial blood $(\mathrm{mm} \mathrm{Hg})$ 
Table 2. ARDSnet mechanical ventilation strategy [30]

\begin{tabular}{lccccccccc}
\hline $\mathrm{FiO}_{2}$ & 0,3 & 0,4 & 0,4 & 0,5 & 0,5 & 0,6 & 0,7 & 0,7 & 0,7 \\
$\mathrm{PEEP}$ & 5 & 5 & 8 & 8 & 10 & 10 & 10 & 12 & 14 \\
$\mathrm{FiO}_{2}$ & 0,8 & 0,9 & 0,9 & 0,9 & 1,0 & & & & \\
$\mathrm{PEEP}$ & 14 & 14 & 16 & 18 & $18-24$ & & & & \\
\hline
\end{tabular}

$\mathrm{FiO}_{2}$ — oxygen concentration in the respiratory mixture (in decimal numbers); PEEP — positive end-expiratory pressure

oxygenation of the patient's blood [26]. It seems that subjects with healthy lungs can start ventilation with PEEP $=5 \mathrm{cmH}_{2} \mathrm{O}$, as this mimics the natural PEEP and protects against the harmful effects of its absence [27]. The problem arises in treatment of ARDS (Table 1) where there is a massive lung deterioration and PEEP values must be high enough to expand the collapsed lungs and, thus ensure normal oxygenation. The ART study looked at patients with ARDS ventilated with an open lung ventilation strategy using the so-called “open lung ventilation” Recruitment manoeuvres (one-time lifting of PEEP pressures to a value of $45 \mathrm{cmH}_{2} \mathrm{O}$ ) and PEEP titration, following the principle of obtaining maximum static compliance (Cstat $=\mathrm{V}_{\mathrm{T}} /$ Pplat). The control group in this study was a group of patients treated with ARDSnet (Table 2) using low PEEP and low $\mathrm{V}_{\mathrm{T}}$ values. Not only did the study experience three sudden cardiac arrests due to recruitment manoeuvres, a higher mortality rate in the study group (in patients with moderate ARDS) was observed [28]. This calls into question the concept of ARDS treatment of "lung opening" [29] and begins a discussion on a new look, involving minimal deformation of the lungs with low or moderate PEEP values (up to $15 \mathrm{cmH}_{2} \mathrm{O}$ ) [23].

The respiratory rate (RR) should ensure the correct elimination of carbon dioxide from the body, so this variable should be adjusted to the results of carbon dioxide pressure $\left(\mathrm{pCO}_{2}\right)$ in blood gas. $\mathrm{PCO}_{2}$ pressure is considered to be normal between 35-45 mm Hg (normocapnia) [31]. The breathing rate of $8-12 / \mathrm{min}$ is generally sufficient in patients without lung damage, mainly in the operating room [32]. Ventilation of patients with ARDS following LPV principles, due to low $V_{T}$ values, often requires an increase in RR. Thus, in patients with ARDS, the ventilation rate can be up to $35 / \mathrm{min}$ [30]. It should be remembered that the RR parameter is also present in the formula for the power of ventilation and its rise contributes to the growth of the MP, therefore, increases the risk of VILI: the animal model study showed that ventilation, even with very harmful volumes, depending on the breath frequency, can significantly model the risk of death [33]. In order to reduce VILI in ARDS patients, limiting RR to $\sim 30$ breaths/min may result in the so-called permissive hypercapnia [11], with the development of respiratory acidosis.

The oxygen concentration in the breathing mixture during mechanical ventilation can range from $21 \%$ to $100 \%(0.21-1.0)$. It should be remembered, however, that due to the harmful effects of aerobic radicals and resorption atelectasis, it is recommended not to increase the oxygen fraction $\left(\mathrm{FiO}_{2}\right)$ above 0.6 [34]. There are studies documenting that hyperoxia increases mortality in intensive care units [35]. For this reason, a conservative oxygen therapy strategy is recommended to maintain oxygen pressure in the blood $\left(\mathrm{pO}_{2}\right)$ within $70-100 \mathrm{~mm} \mathrm{Hg}$ and saturation $\left(\mathrm{SpO}_{2}\right)$ at $94-98 \%$ [36]. For ARDS patients, stricter values can be used: $55-80 \mathrm{~mm} \mathrm{Hg}$ and $88-95 \%$, respectively [30].

\section{Non-invasive ventilation (NIV)}

In recent years, the importance of non-invasive ventilation has been growing, both in hospital wards and in home therapy [37]. There are reports that this method may be the first-line treatment in different types of acute respiratory failure (ARF) [38]. One ought to remember that the rules of invasive ventilation in the ICU cannot be directly transmitted to non-invasive ventilation (NIV). Non-invasive ventilation differs from invasive ventilation primarily by the lack of the need to put on an artificial respiratory tract (intubation tube), and instead uses special masks (nasal, oronasal, full face or ventilation helmets), closely adjacent to the patient's face. In terms of a mere method, NIV is also based on ventilation with positive pressures, but it is necessary to remember that the patient himself must initiate a breath. Calculation of tidal volume during NIV differs as well. It is important to note that due 


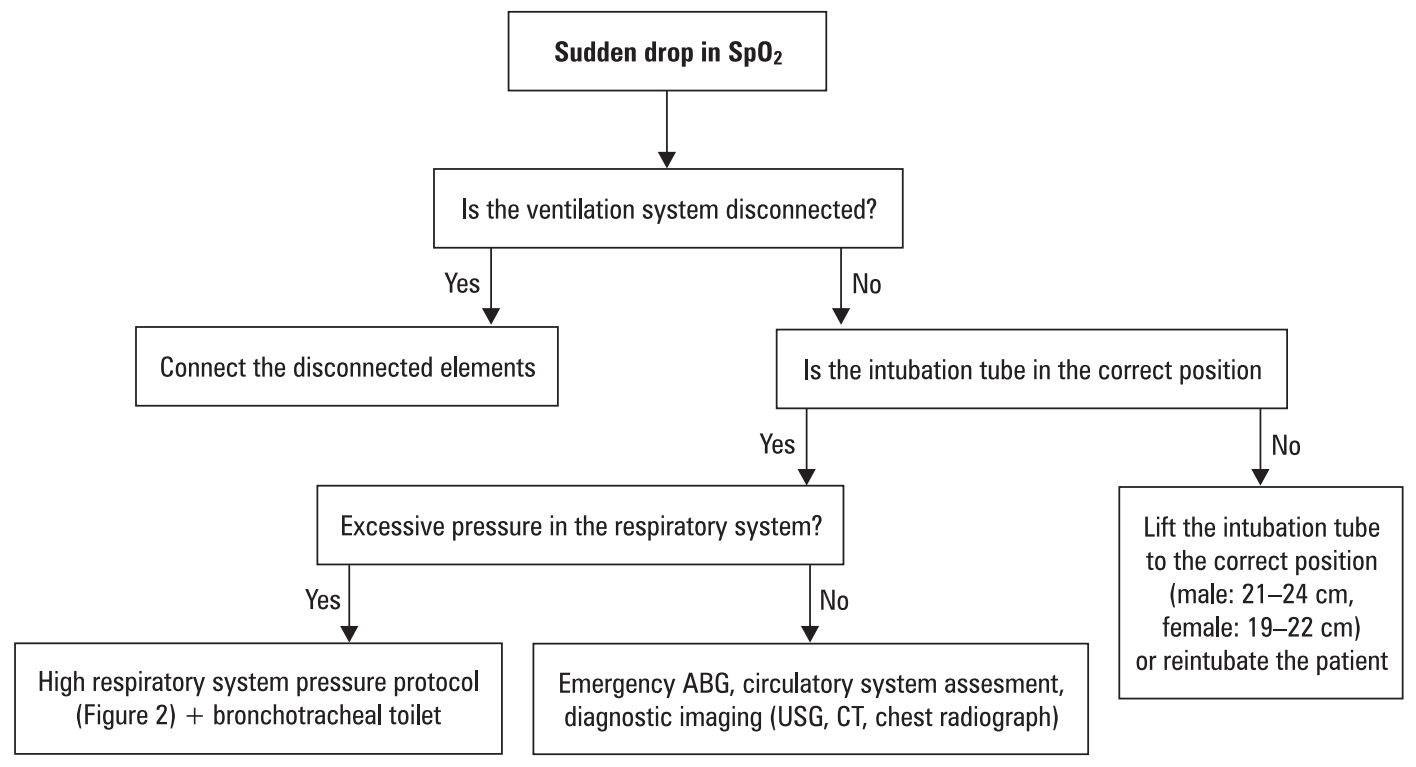

Figure 1. Protocol for a sudden drop in $\mathrm{SpO}_{2}$ management. $\mathrm{ABG}$ - arterial blood gas; $\mathrm{CT}$ - computed tomography; $\mathrm{SpO}_{2}$ — peripheral capillary oxygen saturation; USG — ultrasonography

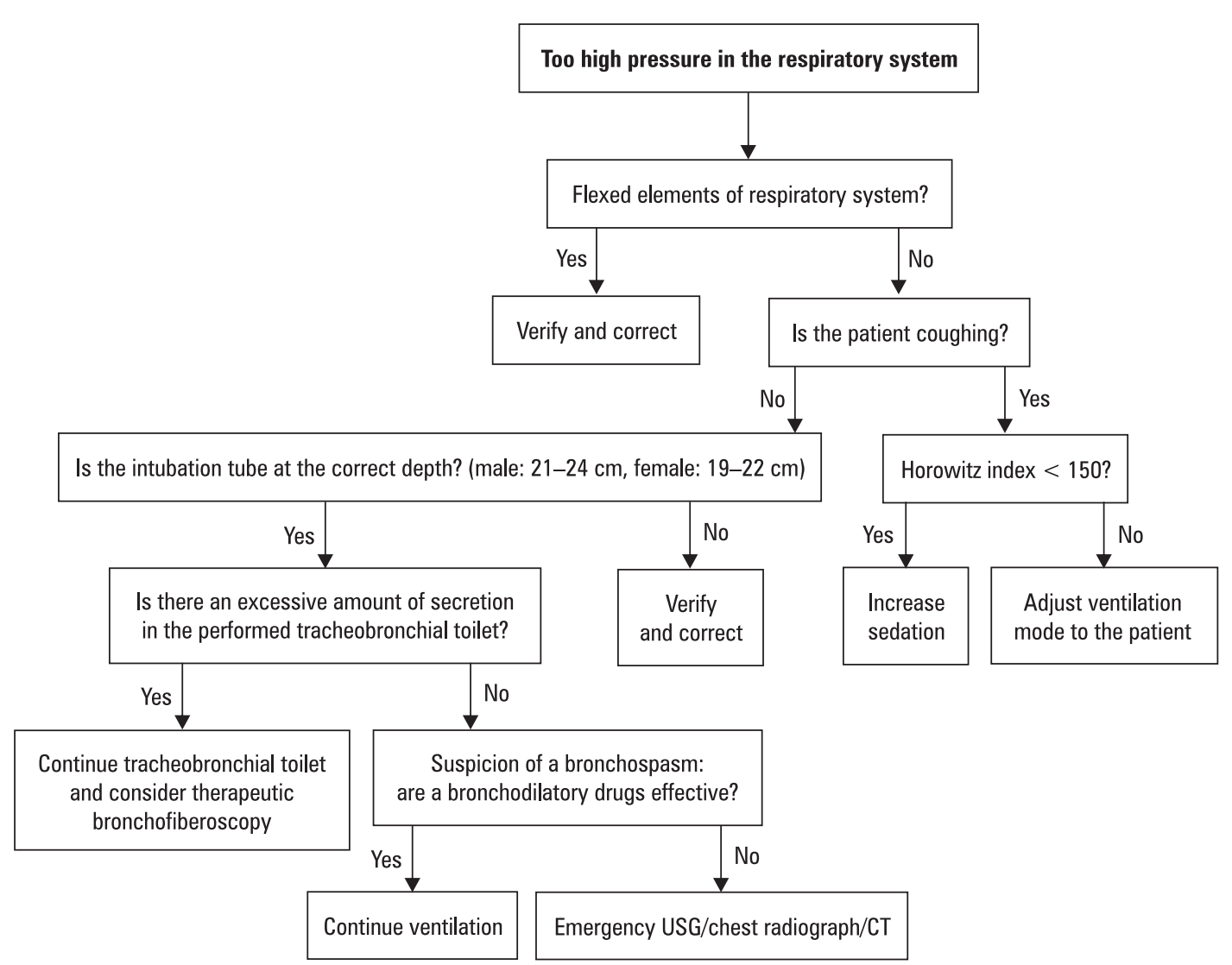

Figure 2. High respiratory system pressure protocol. CT — computed tomography; Horowitz index — the ratio of partial pressure arterial oxygen $\left(\mathrm{PaO}_{2}\right.$ and fraction of inspired oxygen); USG - ultrasonography 


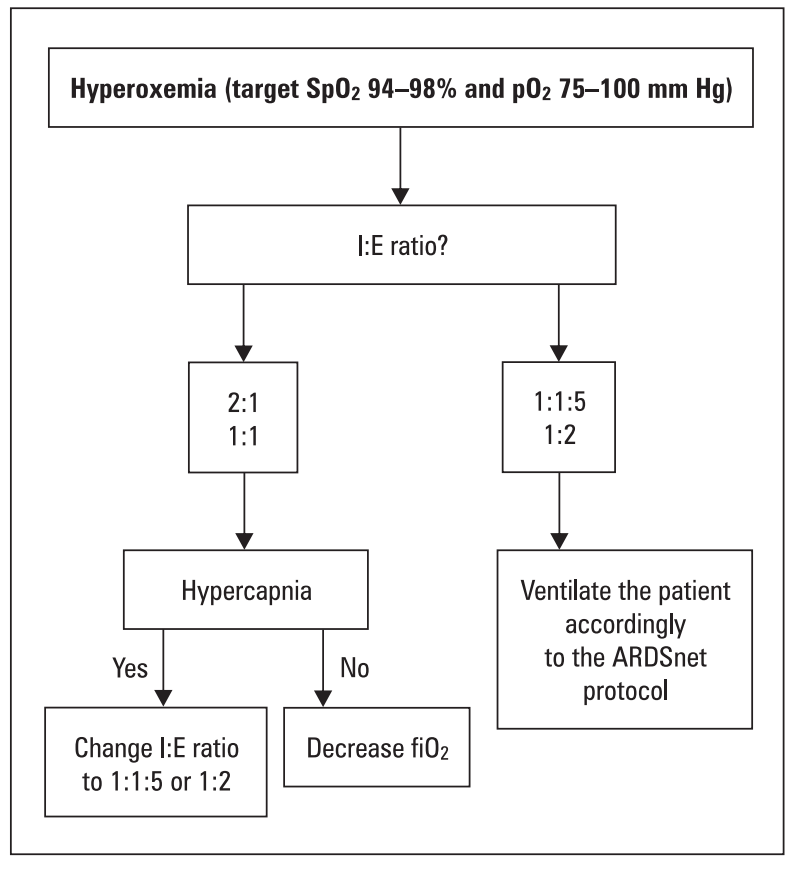

Figure 3. Protocol for hyperoxemia management. $\mathrm{FiO}_{2}$ — oxygen concentration in the respiratory mixture; I:E ratio — inspiratory:expiratory ratio; $\mathrm{pO}_{2}$ - partial pressure of oxygen in the arterial blood $(\mathrm{mm} \mathrm{Hg})$; $\mathrm{SpO}_{2}$ - peripheral capillary oxygen saturation

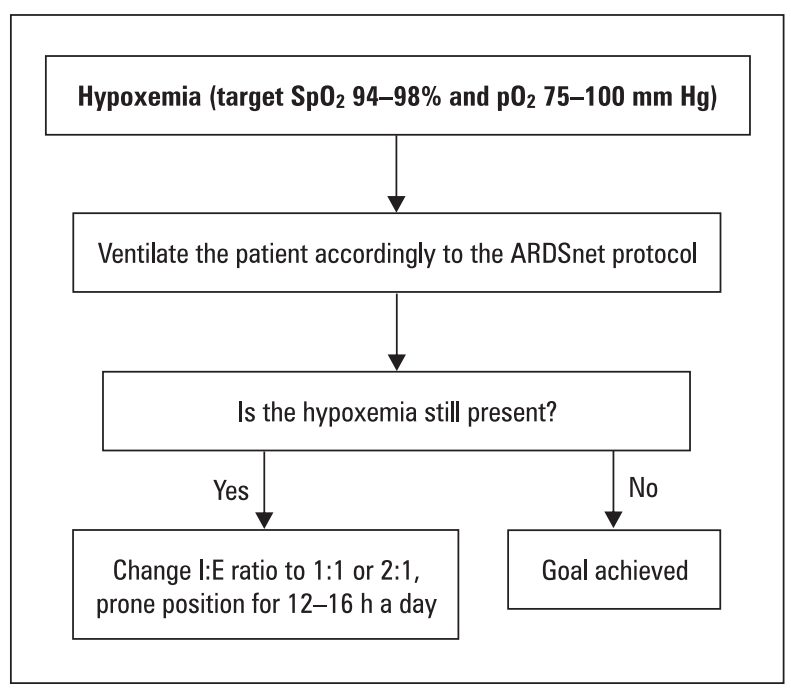

Figure 4. Protocol for hypoxemia management. I:E ratio - inspiratory:expiratory ratio; $\mathrm{pO}_{2}$ - partial pressure of oxygen in the arterial blood $(\mathrm{mm} \mathrm{Hg}) ; \mathrm{SpO}_{2}$ - peripheral capillary oxygen saturation

to possible gas leakage via imperfect mask adhesion, inspiratory volume is often higher than the expiratory volume. The biggest advantage of NIV seems to be minimising the risk of ventilator-associated pneumonia [39], although the risk of VILI cannot be eliminated entirely. NIV does not require sedation and can be used periodically (one-, two-hour sessions, ventilation during sleep). As well as invasive ventilation, NIV meets the basic assumptions of respiratory support as it reduces respiratory work (WOB), facilitates the procurement of $\mathrm{O}_{2}, \mathrm{CO}_{2}$ removal and expands collapsed regions of the lung.

Current indications for starting NIV for ARF are clearly described in the European Respiratory Society and American Thoracic Society clinical practice guidelines published in 2017 [40]. The major indication is the exacerbation of chronic obstructive pulmonary disease (COPD). Support for the patient with non-invasive ventilation reduces dyspnoea, tachypnoea, improves $\mathrm{V}_{\mathrm{T}}$, decreases $\mathrm{pCO}_{2}$ and faster normalises $\mathrm{pH}$ [41]. Non-invasive ventilation in COPD reduces mortality and the need for intubation [42]. Another indication for NIV is cardiogenic pulmonary oedema, as it not only improves blood oxygenation but also reduces the afterload of the left ventricle by optimising transmural pressure. It reduces the need for oxygen in the heart muscle, which translates into an improvement in prognosis [43].

Furthermore, an interesting indication for NIV is an ARF in patients undergoing immunosuppression. It has been proven that in individuals during immunosuppressive treatment (e.g. after organ transplantations) who developed acute respiratory failure, the use of NIV led to intubation avoidance, shortest treatment time and reduced mortality [44]. Another indication for NIV is weaning from mechanical ventilation, as it helps to avoid reintubation, shortens the length of stay in the ICU and reduces the incidence of pneumonia [45]. Finally, ARF as a postoperative complication or ARF as a result of lung injury are other essential indications for NIV [40]. In addition to the above-mentioned main indications, there are still many additional ones, namely neuromuscular diseases, chest injuries, kyphoscoliosis, obstructive sleep apnoea, obesity hypoventilation syndrome) [46-48]. NIV is absolutely contraindicated in patients without effective respiratory drive, with impaired consciousness, in those with unstable haemodynamics and in people at risk of aspiration of food content [49].

Selection of a proper interface that fits properly is of paramount importance for the success of NIV [50]. A significant risk of NIV failure is the mismatch of masks and helmets, which must stick tightly to the patient's face. An oversight in this matter can lead to a critical escape of gases from the system and result in a decline of breath support. It should also be remembered that a mask 


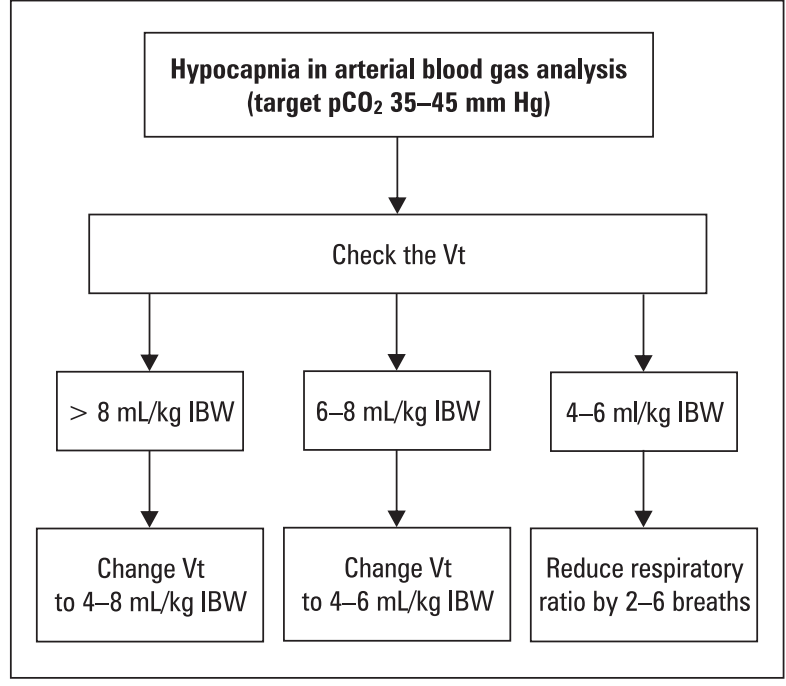

Figure 5. Protocol for hypocapnia management. IBW - ideal body weight; $\mathrm{pCO}_{2}$ - partial pressure of carbon dioxide in the arterial blood $(\mathrm{mm} \mathrm{Hg}) ; \mathrm{Vt}$ - tidal volume

that is too tight or using NIV for too long can lead to serious facial skin damage. In the acute setting, oronasal or full face masks are preferable to nasal masks because dyspneic patients are mouth breathers, predisposing to greater air leakage during nasal mask ventilation [50]. In nonhypercapnic patients, helmet application may be preferred [50].

\section{Basic protocols for the most common disruptions in respiratotherapy}

Finally, a simple pack of protocols for most frequent problems occurring during invasive mechanical ventilation should be learned by all practitioners providing MV (Figure 1-6). For NIV, a modified algorithm should be applied (Figure 7).

\section{Conclusions}

Respiratotherapy includes the integration of many components, the most important of which

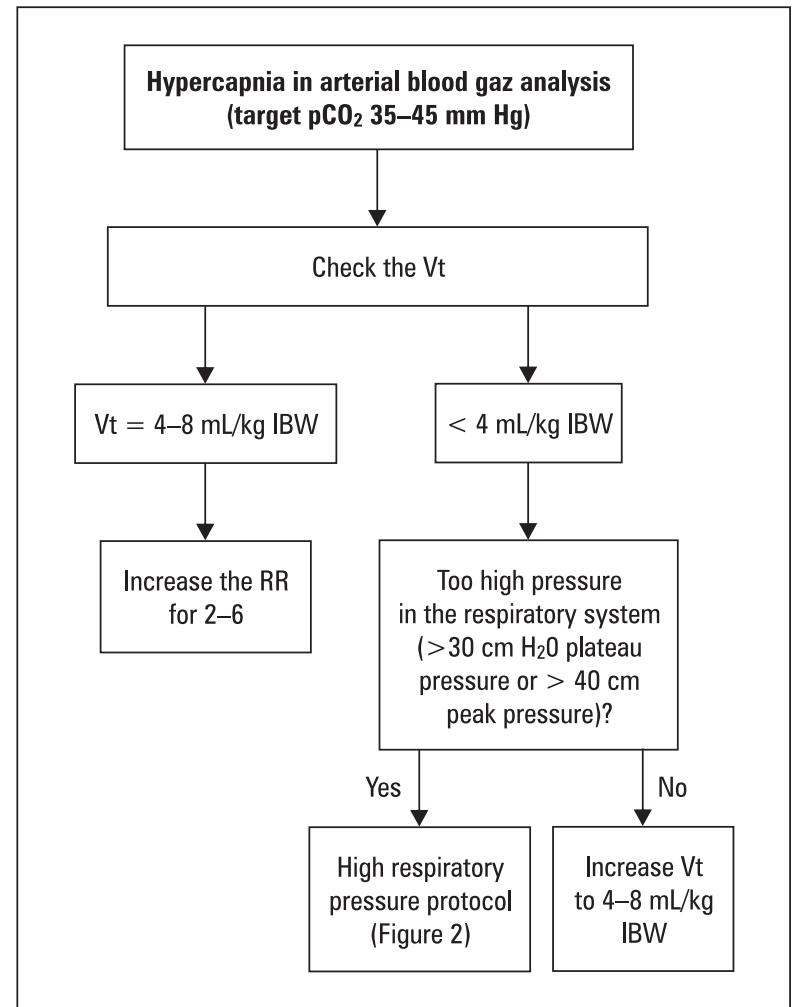

Figure 6. Protocol for hypercapnia management. IBW - ideal body weight; $\mathrm{pCO}_{2}$ - partial pressure of carbon dioxide in the arterial blood $(\mathrm{mm} \mathrm{Hg}) ; \mathrm{RR}$ — respiratory rate; $\mathrm{Vt}$ — tidal volume

remains the patient. Be aware of the limitations and dangers of positive pressure, which, despite being at odds with the physiological way of breathing, is now the most common method of respiratory support in respiratory failure. Ventilation should be adapted to the patient according to personalised therapy. Basic knowledge of mechanical ventilation is essential for doctors specialising in other fields than anaesthesiology and intensive therapy, especially to those before the planned internship at the ICU.

\section{Conflict of interest}

None declared. 


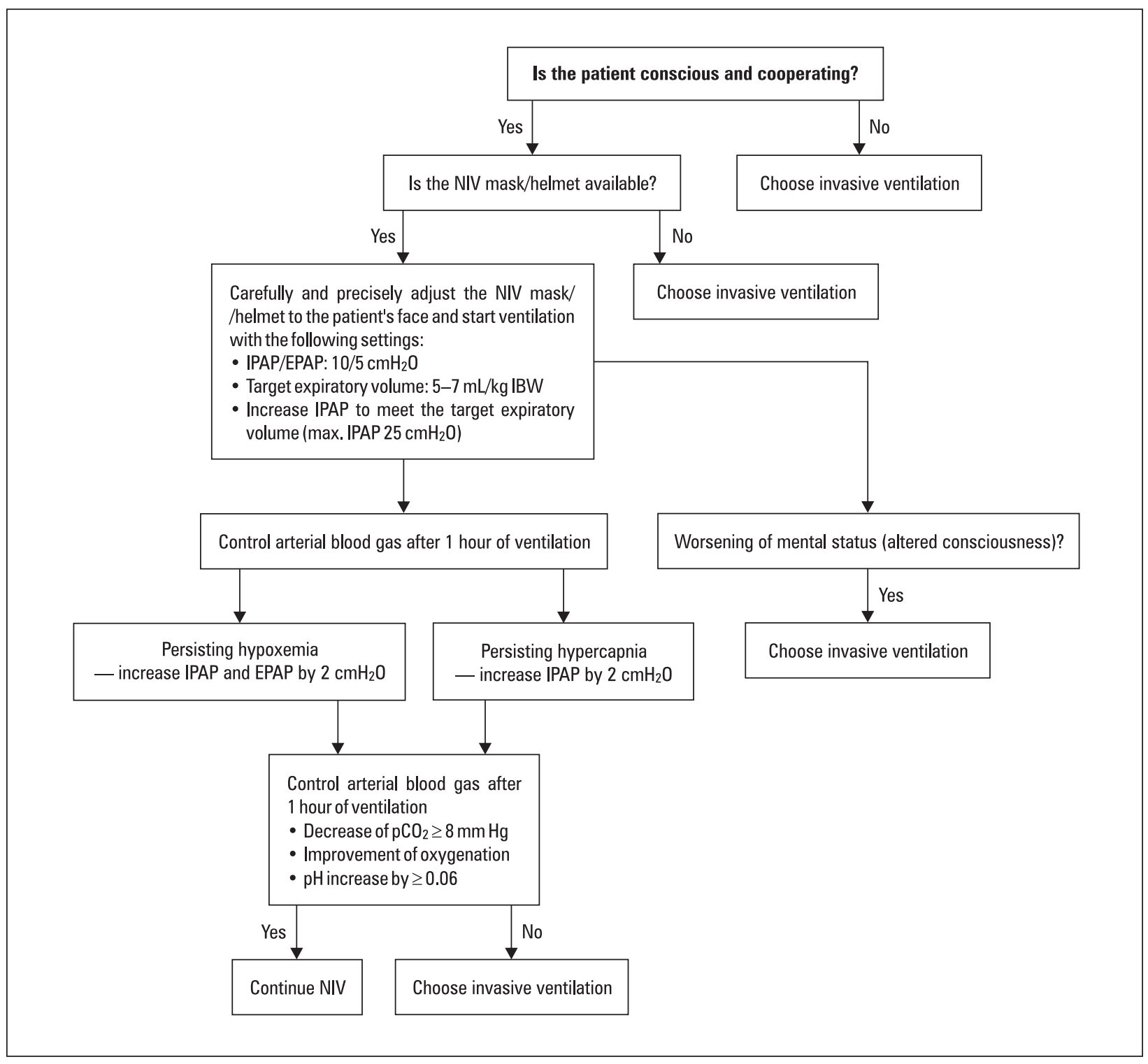

Figure 7. Protocol for management of acute respiratory failure using non-invasive ventilation. EPAP — expiratory positive airway pressure; IBW — ideal body weight; IPAP — inspiratory positive airway pressure; NIV — non-invasive ventilation; $\mathrm{pCO}_{2}$ — partial pressure of carbon dioxide $(\mathrm{mm} \mathrm{Hg}) ; \mathrm{Vt}$ — tidal volume

\section{References:}

1. Ricard JD. Barotrauma during mechanical ventilation: why aren't we seeing any more? Intensive Care Med. 2004; 30(4): 533-535, doi: 10.1007/s00134-004-2186-8, indexed in Pubmed: 14985954.

2. Dreyfuss D, Basset G, Soler P, et al. Intermittent positive-pressure hyperventilation with high inflation pressures produces pulmonary microvascular injury in rats, Am Rev Respir Dis. 1985; 132: 880-884.

3. Pierrakos C, Karanikolas M, Scolletta S, et al. Acute respiratory distress syndrome: pathophysiology and therapeutic options. J Clin Med Res. 2012; 4(1): 7-16, doi: 10.4021/jocmr761w, indexed in Pubmed: 22383921.

4. Amato MB, Barbas CS, Medeiros DM, et al. Effect of a protective-ventilation strategy on mortality in the acute respiratory distress syndrome. N Engl J Med. 1998; 338(6): 347-354, doi: 10.1056/NEJM199802053380602, indexed in Pubmed: 9449727.

5. Tremblay L, Valenza F, Ribeiro SP, et al. Injurious ventilatory strategies increase cytokines and c-fos m-RNA expression in an isolated rat lung model. J Clin Invest. 1997; 99(5): 944-952, doi: 10.1172/JCI119259, indexed in Pubmed: 9062352.
6. Mead J, Takishima T, Leith D. Stress distribution in lungs: a model of pulmonary elasticity. J Appl Physiol. 1970; 28(5): 596-608, doi: 10.1152/jappl.1970.28.5.596, indexed in Pubmed: $\underline{5442255}$.

7. Tremblay LN, Slutsky AS. Ventilator-induced injury: from barotrauma to biotrauma. Proc Assoc Am Physicians. 1998; 110(6): 482-488, indexed in Pubmed: 9824530.

8. Chu EK, Whitehead T, Slutsky AS. Effects of cyclic opening and closing at low- and high-volume ventilation on bronchoalveolar lavage cytokines. Crit Care Med. 2004; 32(1): 168174, doi: 10.1097/01.CCM.0000104203.20830.AE, indexed in Pubmed: 14707576.

9. Slutsky AS, Tremblay LN. Multiple system organ failure. Is mechanical ventilation a contributing factor? Am J Respir Crit Care Med. 1998; 157(6 Pt 1): 1721-1725, doi: 10.1164/ajrccm.157.6.9709092, indexed in Pubmed: 9620897.

10. Gattinoni L, Tonetti T, Cressoni M, et al. Ventilator-related causes of lung injury: the mechanical power. Intensive Care Med. 2016; 42(10): 1567-1575, doi: 10.1007/s00134-016-45052, indexed in Pubmed: 27620287.

11. Suratt BT, Eisner MD, Calfee CS, et al. Ventilation with lower tidal volumes as compared with traditional tidal volumes 
for acute lung injury and the acute respiratory distress syndrome. N Engl J Med. 2000; 342(18): 1301-1308, doi: 10.1056/ NEJM200005043421801, indexed in Pubmed: 10793162.

12. Cressoni M, Gotti M, Chiurazzi C, et al. Mechanical power and development of ventilator-induced lung injury. Anesthesiology. 2016; 124(5): 1100-1108, doi: 10.1097/ ALN.0000000000001056, indexed in Pubmed: 26872367.

13. Pelosi P. Close the lungs and keep them closed to minimize VILI:PRO, 8th Dräger Advanced Ventilation Symposium 2019. London 24.06.2019.

14. Ferguson ND, Fan E, Camporota L, et al. The Berlin definition of ARDS: an expanded rationale, justification, and supplementary material. Intensive Care Med. 2012; 38(10): 15731582, doi: 10.1007/s00134-012-2682-1, indexed in Pubmed: 22926653 .

15. Serpa Neto A, Cardoso SO, Manetta JA, et al. Association between use of lung-protective ventilation with lower tidal volumes and clinical outcomes among patients without acute respiratory distress syndrome: a meta-analysis. JAMA. 2012; 308(16): 1651-1659, doi: 10.1001/iama.2012.13730, indexed in Pubmed: 23093163.

16. Fuller BM, Mohr NM, Drewry AM, et al. Lower tidal volume at initiation of mechanical ventilation may reduce progression to acute respiratory distress syndrome: a systematic review. Crit Care. 2013; 17(1): R11, doi: 10.1186/cc11936, indexed in Pubmed: 23331507.

17. Villar J, Martín-Rodríguez C, Domínguez-Berrot AM, et al. A quantile analysis of plateau and driving pressures: effects on mortality in patients with acute respiratory distress syndrome receiving lung-protective ventilation. Crit Care Med. 2017; 45(5): 843-850, doi: 10.1097/CCM.0000000000002330, indexed in Pubmed: 28252536.

18. Amato MBP, Meade MO, Slutsky AS, et al. Driving pressure and survival in the acute respiratory distress syndrome. N Engl J Med. 2015; 372(8): 747-755, doi: 10.1056/NEJMsa1410639, indexed in Pubmed: 25693014

19. Güldner A, Braune A, Ball L, et al. Comparative effects of volutrauma and atelectrauma on lung inflammation in experimental acute respiratory distress syndrome. Crit Care Med. 2016; 44(9): e854-e865, doi: 10.1097/CCM.0000000000001721, indexed in Pubmed: 27035236.

20. Maciejewski D. Podstawowe tryby wentylacji mechanicznej. In: Wentylacja mechaniczna - teoria i praktyka. Maciejewski D, Wojnar-Gruszka K (ed.). -medica press, Bielsko-Biała 2016.

21. Chiumello D, Cressoni M, Carlesso E, et al. Lung stress and strain during mechanical ventilation for acute respiratory distress syndrome. Am J Respir Crit Care Med. 2008; 178(4): 346355, doi: 10.1164/rccm.200710-15890C, indexed in Pubmed: 18451319

22. Pelosi P, Rocco PR, Gama de Abreu M. Close down the lungs and keep them resting to minimize ventilator-induced lung injury. Crit Care. 2018; 22(1): 72, doi: 10.1186/s13054-0181991-3, indexed in Pubmed: 29558993.

23. Schmitt JM, Vieillard-Baron A, Augarde R, et al. Positive end-expiratory pressure titration in acute respiratory distress syndrome patients: impact on right ventricular outflow impedance evaluated by pulmonary artery Doppler flow velocity measurements. Crit Care Med. 2001; 29(6): 1154-1158, doi: 10.1097/00003246-200106000-00012, indexed in Pubmed: 11395592.

24. Puybasset L, Gusman P, Muller JC, et al. Regional distribution of gas and tissue in acute respiratory distress syndrome. I. Consequences for lung morphology. CT Scan ARDS Study Group. Intensive Care Med. 2000; 26(7): 857-869, doi: 10.1007/ s001340051274, indexed in Pubmed: 10990099.

25. Hemmes SNT, Gama de Abreu M, Pelosi P, et al. High versus low positive end-expiratory pressure during general anaesthesia for open abdominal surgery (PROVHILO trial): a multicentre randomised controlled trial. Lancet. 2014; 384(9942): 495-503, doi: 10.1016/S0140-6736(14)60416-5, indexed in Pubmed: 24894577.

26. Guo L, Wang W, Zhao N, et al. Lung ventilation strategies for acute respiratory distress syndrome: a systematic review and network meta-analysis. Sci Rep. 2016; 6(1): 22855, doi: 10.1038/srep22855, indexed in Pubmed: 26955891.
27. Manzano F, Fernández-Mondéjar E, Colmenero M, et al. Positive-end expiratory pressure reduces incidence of ventilator-associated pneumonia in nonhypoxemic patients. Crit Care Med. 2008; 36(8): 2225-2231, doi: 10.1097/CCM.0b013e31817b8a92, indexed in Pubmed: 18664777.

28. Cavalcanti A, Suzumura É, Laranjeira L, et al. Effect of lung recruitment and titrated positive end-expiratory pressure (PEEP) vs low PEEP on mortality in patients with acute respiratory distress syndrome. JAMA. 2017; 318(14): 1335, doi: 10.1001 jama.2017.14171.

29. Lachmann B. Open up the lung and keep the lung open. Intensive Care Med. 1992; 18(6): 319-321, doi: 10.1007 BF01694358, indexed in Pubmed: 1469157.

30. ARDS Clinical Network Mechanical Ventilation Protocol Summary. Available online: www.ardsnet.org/files/ventilator_protocol_2008-07.pdf. [Last accessed: 14.12.2019].

31. Normal Reference Range Table. Available online: https://web. archive.org/web/19981202040948/http://pathcuric1.swmed. edu:80/PathDemo/NRRT.html. [Last accessed: 10.01.2020].

32. Gutkowski P, Konturek S. Fizjologia oddychania. W: Fizjologia człowieka. Podręcznik dla studentów medycyny. Konturek S (ed.). Elsevier, Wrocław 2013: 235-303.

33. Cressoni M, Gotti M, Chiurazzi C, et al. Mechanical power and development of ventilator-induced lung injury. Anesthesiology. 2016; 124(5): 1100-1108, doi: 10.1097/ ALN.0000000000001056, indexed in Pubmed: 26872367.

34. Mach WJ, Thimmesch AR, Pierce JT, et al. Consequences of hyperoxia and the toxicity of oxygen in the lung. Nurs Res Pract. 2011; 2011: 260482, doi: 10.1155/2011/260482, indexed in Pubmed: 21994818.

35. Ni YN, Wang YM, Liang BM, et al. The effect of hyperoxia on mortality in critically ill patients: a systematic review and meta analysis. BMC Pulm Med. 2019; 19(1): 53, doi: 10.1186/ s12890-019-0810-1, indexed in Pubmed: 30808337.

36. Girardis M, Busani S, Damiani E, et al. Effect of conservative vs conventional oxygen therapy on mortality among patients in an intensive care unit: the oxygen-icu randomized clinical trial. JAMA. 2016; 316(15): 1583-1589, doi: 10.1001 jama.2016.11993, indexed in Pubmed: 27706466.

37. Pierson DJ. History and epidemiology of noninvasive ventilation in the acute-care setting. Respir Care. 2009; 54(1): 40-52, indexed in Pubmed: 19111105.

38. Gregoretti C, Pisani L, Cortegiani A, et al. Noninvasive ventilation in critically ill patients. Crit Care Clin. 2015; 31(3): 435-457, doi: 10.1016/j.ccc.2015.03.002, indexed in Pubmed: 26118914.

39. Keenan SP, Sinuff T, Burns K, et al. Clinical practice guidelines for the use of noninvasive positive-pressure ventilation and noninvasive continuous positive airway pressure in the acute care setting. Canadian Medical Association Journal. 2011; 183(3): E195-E214, doi: 10.1503/cmaj.100071.

40. Rochwerg B, Brochard L, Elliott MW, et al. Official ERS/ ATS clinical practice guidelines: noninvasive ventilation for acute respiratory failure. Eur Respir J. 2017; 50(2), doi: 10.1183/13993003.02426-2016, indexed in Pubmed: 28860265

41. Brochard L, Isabey D, Piquet J, et al. Reversal of acute exacerbations of chronic obstructive lung disease by inspiratory assistance with a face mask. N Engl J Med. 1990; 323(22): 1523-1530, doi: 10.1056/NEJM199011293232204, indexed in Pubmed: 2122253.

42. Brochard L, Mancebo J, Wysocki M, et al. Noninvasive ventilation for acute exacerbations of chronic obstructive pulmonary disease. N Engl J Med. 1995; 333(13): 817-822, doi: 10.1056 NEJM199509283331301, indexed in Pubmed: 7651472.

43. Pinsky MR, Summer WR, Wise RA, et al. Augmentation of cardiac function by elevation of intrathoracic pressure. J Appl Physiol Respir Environ Exerc Physiol. 1983; 54(4): 950-955, doi: 10.1152/jappl.1983.54.4.950, indexed in Pubmed: 6853301.

44. Huang HB, Xu B, Liu GY, et al. Use of noninvasive ventilation in immunocompromised patients with acute respiratory failure: a systematic review and meta-analysis. Crit Care. 2017; 21(1): 4, doi: 10.1186/s13054-016-1586-9, indexed in Pubmed: 28061910.

45. Nava S, Gregoretti C, Fanfulla F, et al. Noninvasive ventilation to prevent respiratory failure after extubation in highrisk patients. Crit Care Med. 2005; 33(11): 2465-2470, doi: 
10.1097/01.ccm.0000186416.44752.72, indexed in Pubmed: 16276167.

46. Vianello A, Bevilacqua M, Arcaro G, et al. Non-invasive ventilatory approach to treatment of acute respiratory failure in neuromuscular disorders. A comparison with endotracheal intubation. Intensive Care Med. 2000; 26(4): 384-390, doi: 10.1007/s001340051171, indexed in Pubmed: 10872129.

47. Gustafson T, Franklin KA, Midgren B, et al. Survival of patients with kyphoscoliosis receiving mechanical ventilation or oxygen at home. Chest. 2006; 130(6): 1828-1833, doi: 10.1378/ chest.130.6.1828, indexed in Pubmed: 17167004.

48. Masa JF, Mokhlesi B, Benítez I, et al. Long-term clinical effectiveness of continuous positive airway pressure therapy versus non-invasive ventilation therapy in patients with obesity hypoventilation syndrome: a multicentre, open-label, randomised controlled trial. Lancet. 2019; 393(10182): 1721-1732, doi: 10.1016/S0140-6736(18)32978-7, indexed in Pubmed: 30935737.

49. Peñuelas O, Frutos-Vivar F, Esteban A. Noninvasive positive-pressure ventilation in acute respiratory failure. CMAJ. 2007; 177(10): 1211-1218, doi: 10.1503/cmaj.060147, indexed in Pubmed: 17984471.

50. Bello G, De Pascale G, Antonelli M, et al. Noninvasive ventilation for the immunocompromised patient: always appropriate? Curr Opin Crit Care. 2012; 18(1): 54-60, doi: $10.1097 /$ MCC.0b013e32834e7c21, indexed in Pubmed: 22143051. 